\title{
Arundic acid attenuates retinal ganglion cell death by increasing glutamate/aspartate transporter expression in a model of normal tension glaucoma
}

\author{
M Yanagisawa ${ }^{1}$, T Aida ${ }^{1}$, T Takeda ${ }^{1}$, K Namekata ${ }^{2}$, T Harada ${ }^{2}$, R Shinagawa ${ }^{3}$ and K Tanaka ${ }^{*, 1,4,5}$
}

Glaucoma is the second leading cause of blindness worldwide and is characterized by gradual visual impairment owing to progressive loss of retinal ganglion cells (RGCs) and their axons. Glutamate excitotoxicity has been implicated as a mechanism of RGC death in glaucoma. Consistent with this claim, we previously reported that glutamate/aspartate transporter (GLAST)deficient mice show optic nerve degeneration that is similar to that observed in glaucoma. Therefore, drugs that upregulate GLAST may be useful for neuroprotection in glaucoma. Although many compounds are known to increase the expression of another glial glutamate transporter, EAAT2/GLT1, few compounds are shown to increase GLAST expression. Arundic acid is a glial modulating agent that ameliorates delayed ischemic brain damage by attenuating increases in extracellular glutamate. We hypothesized that arundic acid neuroprotection involves upregulation of GLAST. To test this hypothesis, we examined the effect of arundic acid on GLAST expression and glutamate uptake. We found that arundic acid induces GLAST expression in vitro and in vivo. In addition, arundic acid treatment prevented RGC death by upregulating GLAST in heterozygous (GLAST ${ }^{+/-}$) mice. Furthermore, arundic acid stimulates the human GLAST ortholog, EAAT1, expression in human neuroglioblastoma cells. Thus, discovering compounds that can enhance EAAT1 expression and activity may be a novel strategy for therapeutic treatment of glaucoma.

Cell Death and Disease (2015) 6, e1693; doi:10.1038/cddis.2015.45; published online 19 March 2015

Glaucoma affects nearly 70 million individuals worldwide and is one of the major causes of blindness in the developed world. ${ }^{1}$ The most common type of glaucoma is primary open angle glaucoma (POAG), which is characterized by gradual visual impairments owing to progressive loss of retinal ganglion cells (RGCs) and their axons. ${ }^{2}$ Although elevated intraocular pressure (IOP) is a risk factor for glaucoma, IOP elevation is not detected within a subset of POAG patients including those with normal tension glaucoma (NTG). ${ }^{3}$ Moreover, some patients continue to exhibit progressive loss of RGCs even after treatment to reduce IOP. ${ }^{4}$ These findings suggest that non-IOP-dependent factors may contribute to RGC degeneration. To better understand the pathogenesis of glaucoma and to develop improved therapies, it is necessary to discover these unidentified factors.

We previously reported that glutamate/aspartate transporter (GLAST)-deficient (GLAST ${ }^{-/}$and $\mathrm{GLAST}^{+/-}$) mice show spontaneous RGC death and glaucoma-like optic nerve degeneration without developing elevated IOP. ${ }^{5,6}$ The GLAST protein is essential for maintaining the extracellular glutamate concentration below neurotoxic levels ${ }^{7}$ and for regulating glutathione levels in Müller glia by transporting glutamate, ${ }^{8}$ the substrate for glutathione synthesis, into the cells. Thus,
GLAST deficiency results in RGC degeneration owing to excitotoxicity and oxidative stress. Moreover, previous work has shown that glutamate excitotoxicity and oxidative stress are involved in retinal damage in glaucoma. ${ }^{9}$ Furthermore, reportedly, the human GLAST ortholog excitatory amino-acid transporter 1 (EAAT1) is downregulated in the retinas of human patients with glaucoma. ${ }^{10}$ This result suggests that impairments in EAAT1 activity may be related to the pathogenesis of glaucoma. We previously reported that interleukin-1-dependent activation of GLAST increases glutamate uptake by Müller glia and protects RGCs from excitotoxicity. ${ }^{11}$ In addition, glial cell line-derived neurotrophic factor and neuturin-induced upregulation of GLAST in Müller cells is required to protect RGCs following optic nerve transection. ${ }^{12}$ Therefore, discovering new compounds that enhance EAAT1 activity may represent a novel strategy for therapeutic management of glaucoma.

In recent years, several groups have identified clinically useful drugs that activate EAAT2 transcription and translation. ${ }^{13-15}$ In the first study of this kind, Rothstein et al. $^{13}$ reported that a $\beta$-lactam antibiotic, ceftriaxone, is neuroprotective in vitro and in vivo by increasing the expression of EAAT2. Although many compounds are known

\footnotetext{
${ }^{1}$ Laboratory of Molecular Neuroscience, Medical Research Institute, Tokyo Medical and Dental University, 1-5-45 Yushima, Bunkyo-ku, Tokyo 113-8510, Japan; ${ }^{2}$ Visual Research Project, Tokyo Metropolitan Institute of Medical Science, 2-1-6 Kamikitazawa, Setagaya-ku, Tokyo 156-8506, Japan; ${ }^{3}$ Discovery Research Laboratories I, Minase Research Institute, Ono Pharmaceutical Co. Ltd., 1-1, Sakurai 3-chome, Shimamoto-cho, Mishima-gun, Osaka 618-8585, Japan; ${ }^{4}$ The Center for Brain Integration Research, Tokyo Medical and Dental University, 1-5-45 Yushima, Bunkyo-ku, Tokyo 113-8510, Japan and ${ }^{5}$ JST, CREST, 7, Gobancho, Chiyoda-ku, Tokyo 102-0076, Japan ${ }^{*}$ Corresponding author: K Tanaka, Laboratory of Molecular Neuroscience, Medical Research Institute and The Center for Brain Integration Research, Tokyo Medical and Dental University, 1-5-45, Yushima, Bunkyo-Ku, Tokyo 113-8510, Japan. Tel: +81 35803 5846; Fax: +81 35803 5843; E-mail: tanaka.aud@ mri.tmd.ac.jp Abbreviations: GCL, ganglion cell layer; HEK, human embryonic kidney; INL, inner nuclear layer; IOP, intraocular pressure; NTG, normal tension glaucoma; ONL, outer nuclear layer; P, postnatal day; POAG, primary open angle glaucoma; RGC, retinal ganglion cell

Received 05.8.14; revised 22.1.15; accepted 23.1.15; Edited by A Verkhratsky
} 
<smiles>CCCCCCC(CCC)C(=O)O</smiles>

b

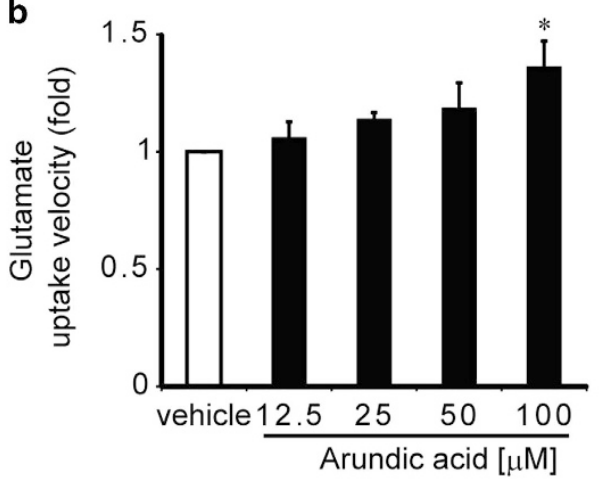

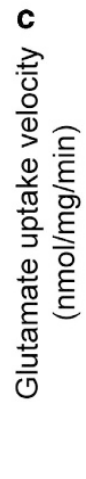

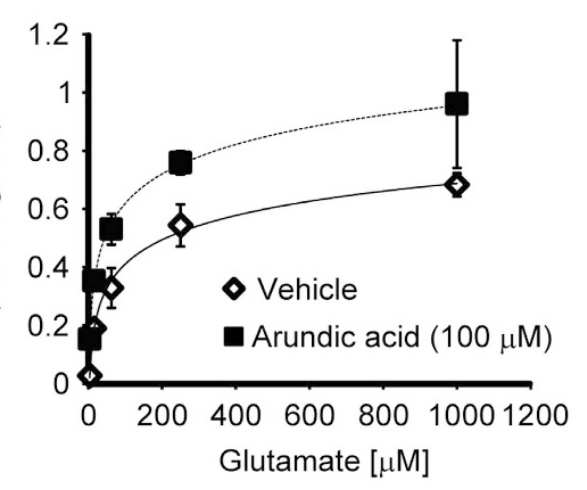

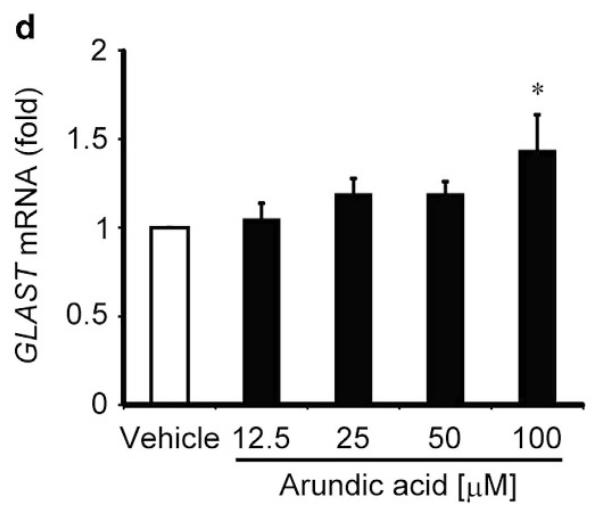

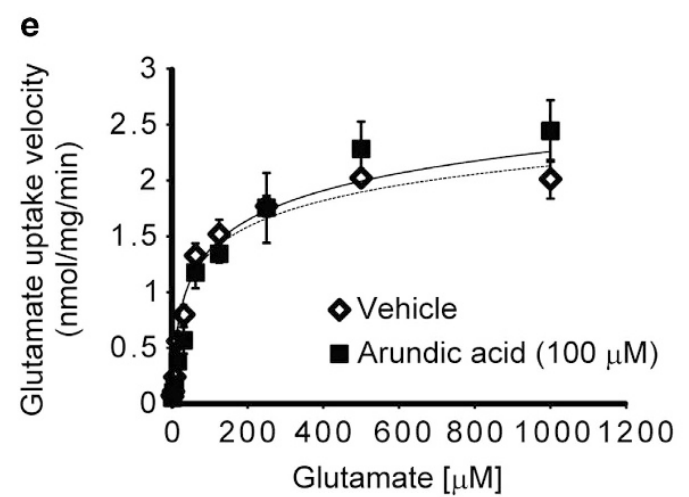

Figure 1 Arundic acid enhances glutamate uptake activity in Müller cells by an increase in the expression of GLAST mRNA. (a) Chemical structure of arundic acid. (b) In primary cultured Müller cells, glutamate transport is significantly increased after 14 days of treatment with $100 \mu \mathrm{M}$ arundic acid. ${ }^{*} P<0.05$ as determined by one-way ANOVA with Tukey-Kramer's post hoc analysis. (c) Representative transport kinetics saturation curves for $\mathrm{L}-\left[3,4-{ }^{3} \mathrm{H}\right]$-glutamate uptake activity in primary cultured Müller cells treated with $100 \mu \mathrm{M}$ arundic acid (closed square) or vehicle alone (open rhombus). Each data point corresponds to the mean \pm S.E.M. of three individual determinations. (d) Effects of arundic acid on GLAST mRNA expression in primary cultured Müller cells. GLAST mRNA expression is significantly increased following $100 \mu \mathrm{M}$ arundic acid treatment. ${ }^{*} P<0.05$ as determined by one-way ANOVA with Dunnett's post hoc analysis. (e) Transport kinetics analysis of glutamate uptake activity by EAAT1-expressing HEK293T cells following treatment with $100 \mu \mathrm{M}$ arundic acid (closed square) or vehicle alone (open rhombus). Data from three independent experiments generated mean values of $44.28 \pm 9.22 \mu \mathrm{M}$ for $K_{\mathrm{m}}$ and $2.04 \pm 0.51 \mathrm{nmol} / \mathrm{mg} / \mathrm{min}$ for $V_{\max }$, in the absence of arundic acid, versus $54.96 \pm 18.57 \mu \mathrm{M}$ for $K_{\mathrm{m}}$ and $2.13 \pm 0.53 \mathrm{nmol} / \mathrm{mg} / \mathrm{min}$ for $V_{\text {max }}$, in the presence of arundic acid treatment. Thus, arundic acid had no effect on the kinetic properties of glutamate uptake by EAAT1-expressing HEK293T cells

to increase EAAT2 expression, few drugs increase the expression of EAAT1/GLAST. ${ }^{16}$ Because of our specific interest in anti-glaucoma therapies, we wish to identify drugs that elevate EAAT1/GLAST expression and activity.

Arundic acid ((2R)-2-propyloctanoic acid, ONO-2506; Figure 1a) was originally discovered through screening for an agent to inhibit synthesis of $\mathrm{S} 100 \beta$ in astrocytes. ${ }^{17} \mathrm{~A}$ previous study showed that arundic acid administration markedly ameliorates brain damage in a transient middle cerebral artery occlusion rat model. ${ }^{18}$ These beneficial effects of arundic acid are associated with marked suppression of delayed extracellular glutamate accumulation in the periinfarct areas. ${ }^{19}$ In searching for a possible mechanism of action, we hypothesized that arundic acid neuroprotection involves upregulation of EAAT1/GLAST.

To explore this hypothesis, we studied the effect of arundic acid on EAAT1/GLAST expression and glutamate uptake activity. These studies demonstrate that arundic acid can induce EAAT1/GLAST expression in vitro and in vivo. In addition, in GLAST heterozygous ( $G L A S T^{+/-}$) mice, treatment with arundic acid prevents RGC death, mediated through upregulation of GLAST.

\section{Results}

Arundic acid increases glutamate uptake in mouse Müller cells by increasing GLAST expression. To explore the postulated effects of arundic acid on glutamate uptake activity, first, we examined glutamate uptake in Müller cells that were prepared from retinas of $\mathrm{C} 57 \mathrm{BL} / 6 \mathrm{~J}$ mice and cultured for 14 days in the presence of $0-100 \mu \mathrm{M}$ arundic acid. The glutamate uptake velocity was significantly increased by $100 \mu \mathrm{M}$ arundic acid treatment (Figure 1b). Figure 1c shows the kinetic analysis of glutamate uptake in the presence and absence of $100 \mu \mathrm{M}$ arundic acid. The $V_{\max }$ value of cells treated with arundic acid was 1.48 times that of cells treated with vehicle alone (Student's $t$-test, $P<0.05$ ), whereas the $K_{\mathrm{m}}$ value was not significantly affected $(42.15 \pm 18.98 \mu \mathrm{M}$ for vehicle alone versus $30.52 \pm 8.67 \mu \mathrm{M}$ for arundic acid). These results suggest that arundic acid increases glutamate uptake activity by increasing $V_{\text {max }}$, without shifting the apparent glutamate affinity. One mechanism for increasing $V_{\text {max }}$ is by increasing transporter expression. In Müller cells, GLAST is the most abundant glutamate transporter subtype. ${ }^{20}$ Thus, we examined whether arundic acid increases GLAST expression in Müller cells by 
quantitative real-time PCR (q RT-PCR). One hundred micromolar arundic acid significantly increased $(P<0.05)$ endogenous GLAST mRNA expression in Müller cells (Figure 1d). The time course study revealed that arundic acid induced GLAST mRNA and protein expression as early as $24 \mathrm{~h}$ posttreatment (Supplementary Figures 1a and b). Because the transport process is driven by ion gradients, an arundic acidmediated increase in glutamate uptake in Müller cells could be achieved indirectly by altering ion gradient across the plasma membrane. To explore this possibility, we examined the effect of arundic acid on glutamate uptake in HEK293T cells transfected with EAAT1 cDNA. In this system, arundic acid treatment did not alter the kinetic properties of EAAT1 (Figure 1e). Together, these results indicate that arundic acid treatment enhances glutamate uptake in Müller cells by increasing GLAST gene expression.
Arundic acid selectively enhances glutamate uptake via GLAST in the retina. To determine whether the effects of arundic acid are similar in vivo, we examined glutamate transporter expression in isolated mouse retinas treated with arundic acid. Three glutamate transporters are expressed around the synapses of RGCs in the plexiform layer, GLAST, GLT1 and excitatory amino-acid carrier 1 (EAAC1). ${ }^{21} \mathrm{We}$ administered arundic acid or vehicle to $\mathrm{GLAST}^{+/-}$mice during postnatal day $(P) 22$ to $P 35$, and evaluated the glutamate transporter expression levels by qPCR. Arundic acid treatment increased GLAST mRNA expression in the retinas of $G L A S T^{+/-}$mice, but did not alter GLT1 or EAAC1 mRNA levels (Figure 2a). Next, we asked whether arundic acid is capable of increasing GLAST protein expression in the retinas of $G L A S T^{+/-}$mice. Using western blot analysis, we found that 14-day arundic acid treatment significantly
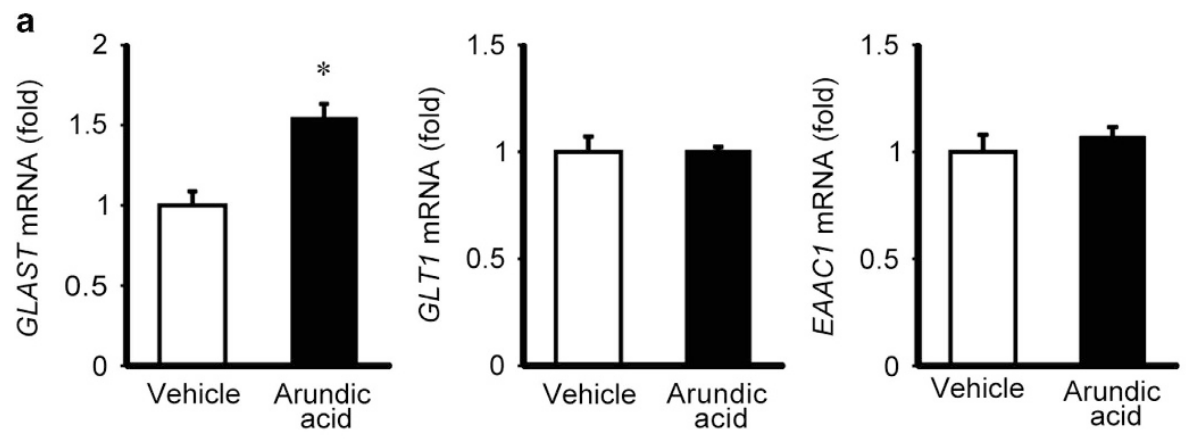

b
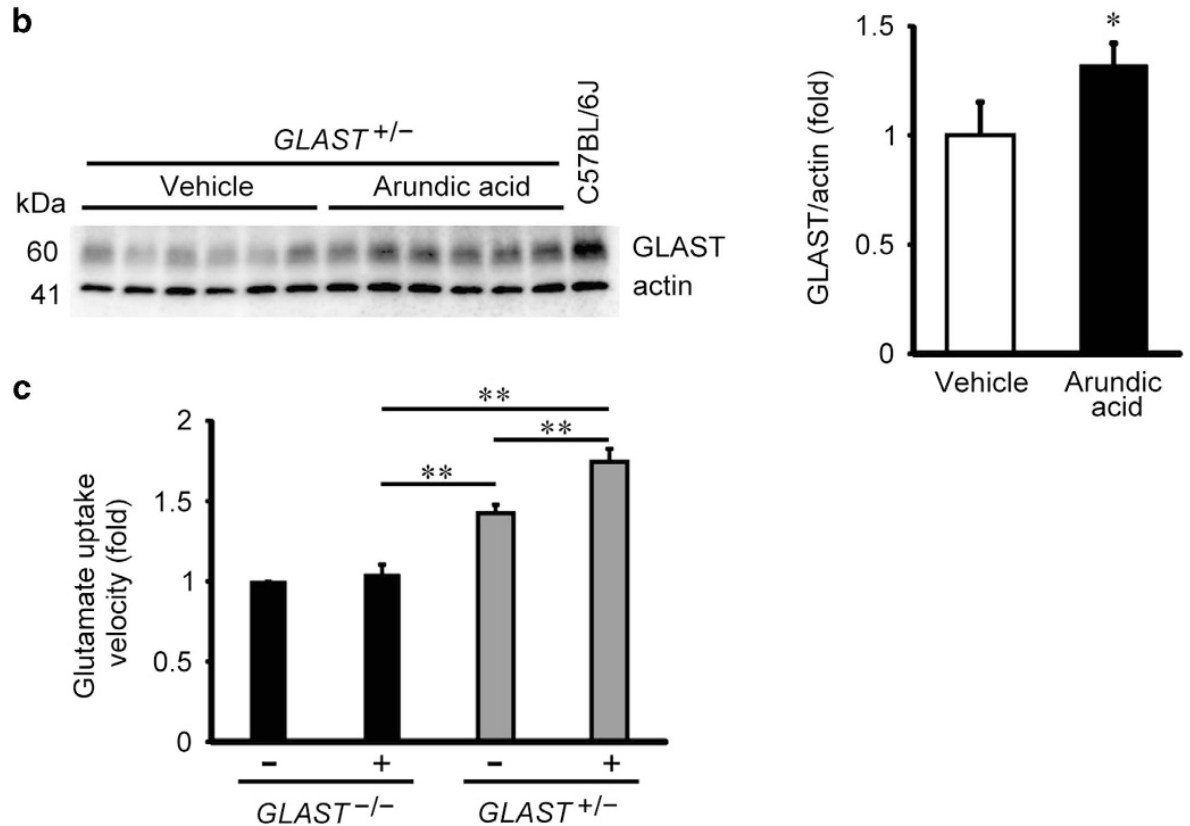

Figure 2 Arundic acid increases GLAST expression and transport activity in the mouse retina. (a) Effects of arundic acid treatment on GLAST, GLT1 and EAAC1 mRNA levels in the retina of GLAST ${ }^{+/-}$mice. Arundic acid (10 mg/kg, given daily from P22 to P35) increased the GLASTmRNA level $(N=6)$, whereas the mRNA levels of GLT1 $(N=6)$ and $\operatorname{EAAC1}(\mathrm{N}=6)$ are unaffected. ${ }^{*} P<0.05$ as determined by a Student's t-test. (b) Arundic acid (10 mg/kg) increases GLAST protein expression in the retina of GLAST ${ }^{+/-}$ mice relative to vehicle-treated control mice $(N=6)$. A representative western blot of GLAST protein expression is shown; the quantified data represent the mean \pm S.E.M. ${ }^{*} P<0.05$ as determined by a Student's $t$-test. (c) Effect of arundic acid on glutamate uptake activity in the retina of GLAST mutant mice. Relative glutamate uptake velocity was quantified from six independent experiments performed in duplicate for each data point. Data represent the mean \pm S.E.M. ${ }^{*} P<0.05,{ }^{* *} P<0.01$ as determined by one-way ANOVA with Tukey-Kramer's post hoc analysis 
increased endogenous GLAST protein expression (Figure 2b). To test whether the increases in GLAST mRNA and protein expression are accompanied by enhanced glutamate transport activity, we conducted L-[3,4- $\left.{ }^{3} \mathrm{H}\right]$-glutamate uptake assays in isolated retinas from $G L A S T^{+/-}$and $G L A S T^{-1-}$ mice. Fourteen-day arundic acid treatment led to a 1.23-fold increase in glutamate uptake in the retinas of $\mathrm{GLAST}^{+/-}$ mice, compared with those treated with vehicle alone. We also observed that arundic acid increased GLAST protein expression and glutamate uptake activity in the retinas of wild-type mice (Supplementary Figures 2a and b). By contrast, arundic acid treatment did not affect glutamate uptake activity in the retinas of $\mathrm{GLAST}^{-1}$ mice (Figure $2 \mathrm{c}$ ). These results suggest that arundic acid treatment increases retinal glutamate uptake activity by selectively increasing GLAST expression in vivo.

Arundic acid alleviates RGC loss by increasing GLAST expression in GLAST heterozygous mice. On the basis of the increased expression of GLAST described above, we hypothesized that arundic acid could be neuroprotective by protecting against RGC degeneration in GLAST-deficient mice. Chronic oral treatment of $G L A S T^{+/-}$mice with arundic acid, starting at 22 days of age, lead to a significant prevention of RGC loss compared with vehicle-treated control $\mathrm{GLAST}^{+/-}$mice (Figure 3). The number of cells in the ganglion cell layer (GCL) of $G L A S T^{+/-}$mice subjected to arundic acid treatment was significantly increased $(438 \pm 8$ cells; $N=6$ ) relative to $G L A S T^{+/-}$mice without arundic acid treatment ( $366 \pm 11$ cells; $N=6$; Figures $3 a$ and b). Neuroprotective effects of arundic acid cannot be seen with GLAST activation when studied in $G L A S T^{-/}$mice. Taken together, these results suggested that arundic acid attenuates RGC loss in $\mathrm{GLAST}^{+/-}$mice by specifically facilitating GLAST expression.

Arundic acid facilitates the endogenous EAAT1 expression in human neuroglioblastoma cells via activating EAAT1 promoter. Although arundic acid can enhance the expression of GLAST in retina of mice, it remains unclear whether arundic acid increases the expression of endogenous EAAT1 in human cells. To study the effect of arundic acid on endogenous EAAT1 expression in human glial cells, $\mathrm{H} 4$ human neuroglioblastoma cells ${ }^{22}$ were incubated with arundic acid for 9 days. EAAT1 mRNA levels were quantified by qPCR. Treatment with 50 and $100 \mu \mathrm{M}$ arundic acid significantly increased EAAT1 mRNA expression in $\mathrm{H} 4$ cells (Figure $4 \mathrm{a}$ ). To better understand the mechanism of action, we examined the effect of arundic acid on the promoter activity of EAAT1 in $\mathrm{H} 4$ cells. Previous studies showed that the full-length human EAAT1 promoter compromised the $2.3 \mathrm{~kb}$ region immediately flanking the 5 '-end of the human EAAT1 gene ${ }^{22}$ and the 3 '-UTR of the human EAAT1 mediated the stimulatory influence of dbcAMP, epidermal growth factor, transforming growth factor $a$ and pituitary adenylate cyclaseactivating polypeptide on EAAT1 expression. ${ }^{23}$ Thus, $\mathrm{H} 4$ cells were transfected with a reporter plasmid containing the full-length human EAAT1 promoter in combination with the $3^{\prime}$-UTR of the human EAAT1 at 6 days after $50 \mu \mathrm{M}$ arundic acid treatment. After 9 days of treatment of arundic acid, the cells were harvested and subjected to a luciferase reporter assay. Arundic acid significantly increased reporter gene activity of a construct containing the full-length human EAAT1 promoter sequence as compared with vehicle-treated controls
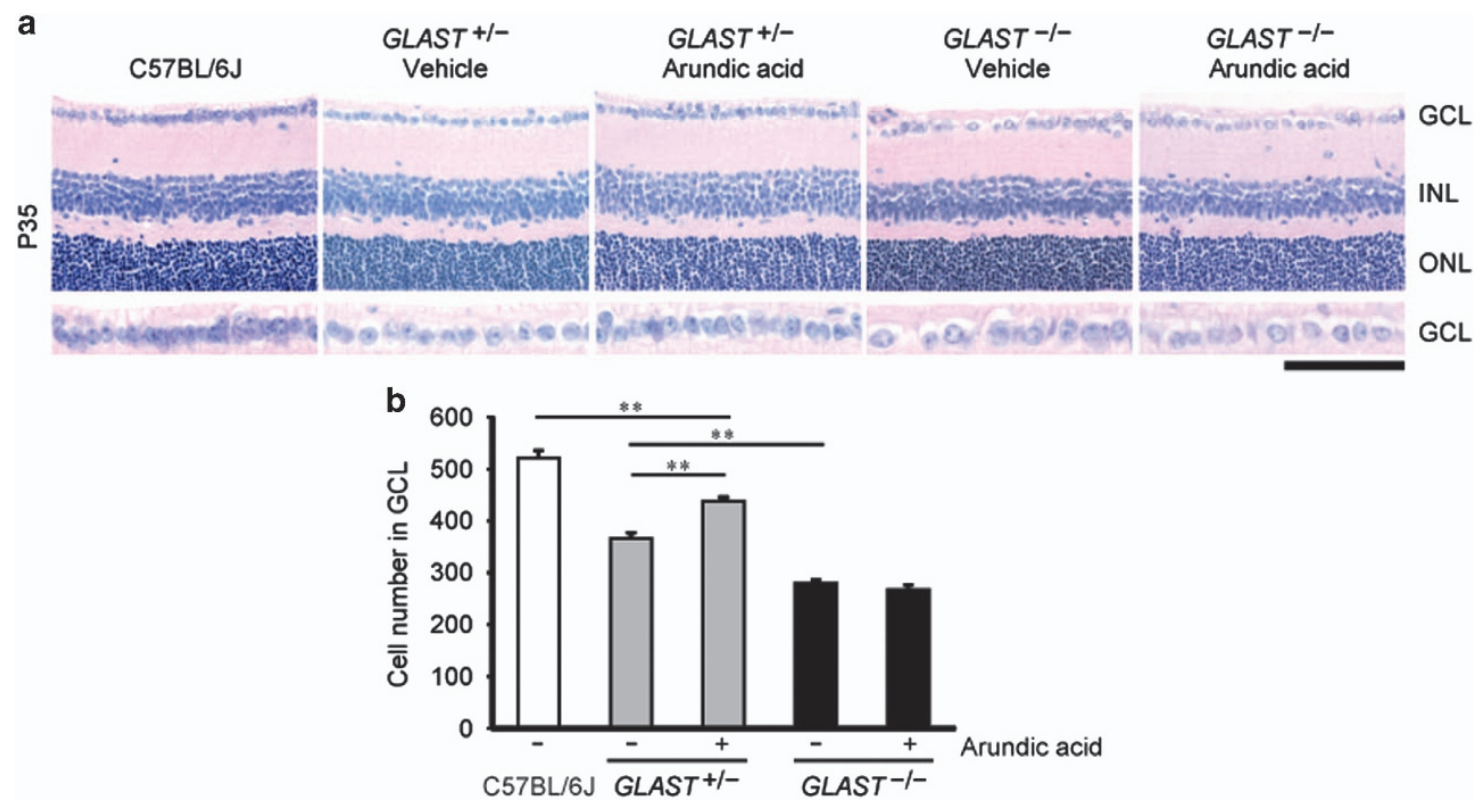

Figure 3 Arundic acid rescues RGC death in $\mathrm{GLAST}^{+/-}$mice by increasing GLAST expression. (a) Hematoxylin and eosin-stained retinal sections from wild-type, $\mathrm{GLAST}^{+/-}$and GLAST ${ }^{-/}$mice at P35, with or without arundic acid $(10 \mathrm{mg} / \mathrm{kg}$ ) treatment. The scale bar represents $100 \mu \mathrm{m}$ and $50 \mu \mathrm{m}$ in the upper and lower panels, respectively. GCL, ganglion cell layer; INL, inner nuclear layer; ONL, outer nuclear layer. (b) Quantitative analyses of the number of neurons in the GCL following arundic acid treatment. The numbers of neurons in the GCL were counted in retinal sections from one ora serrata through the optic nerve to the other ora serrata $(N=6)$. The data represent the mean \pm S.E.M.. ${ }^{* *} P<0.01$ as determined by one-way ANOVA with Tukey-Kramer's post hoc analysis 

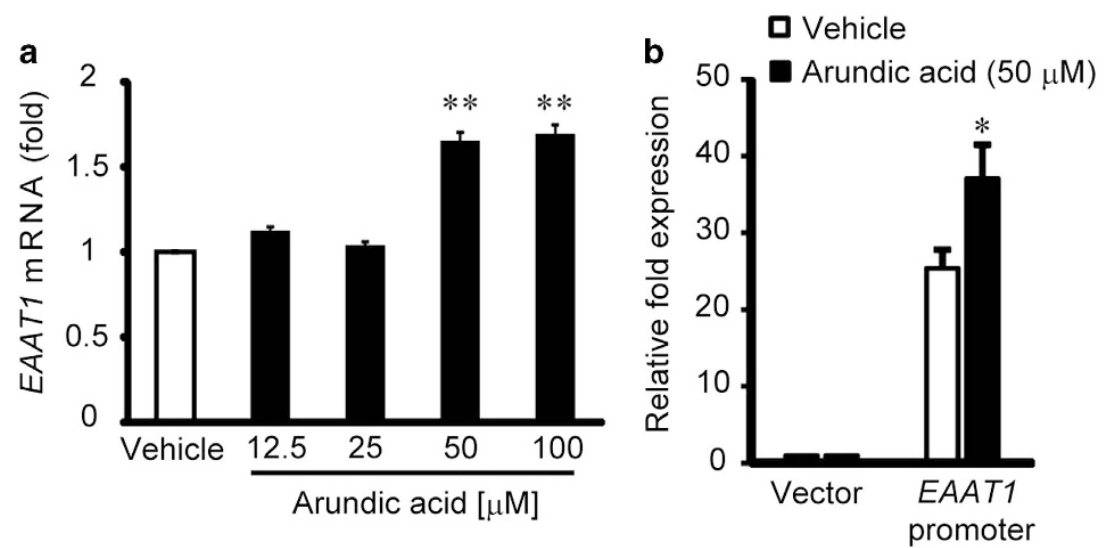

Figure 4 Arundic acid increases EAAT1 mRNA and EAAT1 promoter activity in human neuroglioblastoma $\mathrm{H} 4 \mathrm{cells}$. (a) Arundic acid treatment resulted in an increase in EAAT1 mRNA in the human $\mathrm{H} 4$ cell line, as evaluated by qPCR $(N=4)$. Data represent the mean \pm S.E.M. ${ }^{* \star} P<0.01$ relative to control as determined by one-way ANOVA with Tukey-Kramer's post hoc analysis. (b) Arundic acid activates the EAAT1 promoter. In human $\mathrm{H} 4$ cells transfected with the EAAT1 promoter/luciferase reporter, $50 \mu \mathrm{M}$ arundic acid significantly induced EAAT1 promoter activity $(N=6)$. Data represent the mean \pm S.E.M. ${ }^{*} P<0.05$ as determined by a Student's $t$-test

(Figure 4b). These data suggested that arundic acid can increase glutamate uptake in the human glial cells by activating the genetic promoter for EAAT1.

\section{Discussion}

Our previous study showed that GLAST-deficient mice develop NTG-like phenotypes, ${ }^{5}$ which suggests that GLAST dysfunction may underlie or contribute to RGC loss in glaucoma patients. Importantly, deletion of GLAST in mice results in RGC degeneration without IOP elevation. ${ }^{5}$ Currently, IOP reduction is the only proven treatment of glaucoma. However, it should be noted that some glaucoma patients are still progressive despite sufficient IOP reduction. ${ }^{4}$ Thus, there is an urgent need for the discovery of alternative therapeutic approaches that are independent of IOP reduction and directed at preventing RGC loss. As glutamate excitotoxicity is involved in RGC loss in glaucoma, ${ }^{9,10,24-26}$ drugs capable of increasing GLAST may be useful neuroprotective compounds. In recent years, a number of groups have identified clinically useful drugs that elevate EAAT2 levels. ${ }^{13-15}$ However, there are few available drugs capable of increasing the expression of EAAT1/GLAST. ${ }^{16}$ Various preclinical investigations have demonstrated the manifold beneficial actions of arundic acid against neurological diseases, including ischemic stroke, ${ }^{27}$ Parkinson's disease, ${ }^{28}$ amyotrophic lateral sclerosis ${ }^{29}$ and Alzheimer's disease. ${ }^{30}$ Although a lot of studies have assessed the inhibitory effect of arundic acid on the production and release of $S 100 \beta$ protein from glial cells in these diseases, no study has examined the effect of arundic acid on the expression and activity of glutamate transporters. Because glutamate excitotoxicity is involved in these neurological diseases, ${ }^{31}$ we hypothesized that the neuroprotective properties of arundic acid may, in part, involve the augmentation of EAAT1/GLAST. In this study, we demonstrated that arundic acid increases the EAAT/GLAST levels of the retina. This effect was specific to GLAST and did not alter the other subtypes of glutamate transporters, including the astroglial GLT1 and the neuronal EAAC1. It was reported that the neuroprotective action of arundic acid was mediated exclusively through the modulation of astrocytic function. ${ }^{17}$ In the brain, GLAST and GLT1 are mainly localized in astrocytes. ${ }^{32}$ However, in the retina, GLAST is expressed in Müller cells, whereas GLT1 is expressed only in a restricted set of neurons (mainly cone photoreceptors and cone bipolar cells). ${ }^{20}$ Thus, the selective upregulation of GLAST in the retina by arundic acid can be explained by the selective localization of GLAST in Müller cells, the major type of glial cells in the retina.

A previous study suggested that GLAST is also important for maintaining glutathione levels in Müller cells by transporting glutamate into the cells. ${ }^{5}$ Thus, GLAST dysfunction may lead to RGC degeneration through both excitotoxicity and oxidative stress. Arundic acid protected RGCs from oxidative and glutamate-induced injuries by increasing EAAT1/GLAST expression. Glutamate excitotoxicity and oxidative stress may contribute to retinal damage in various eye diseases, including retinal ischemia, ${ }^{20}$ glaucoma, ${ }^{33,34}$ diabetic retinopathy ${ }^{35}$ and age-related macular degeneration. ${ }^{36}$ In addition, if neurons that contain high concentrations of glutamate are injured, then there can also be secondary excitotoxic damage. Therefore, augmentation of EAAT1/GLAST activity with arundic acid treatment may be a novel strategy for the management of glaucoma and other various forms of retinopathy. Furthermore, we observed that arundic acid enhances the glutamate uptake activity and expression of glial glutamate transporters, GLT1 and GLAST, in the cerebral cortex of wild-type mice (Supplementary Figures $3 a$ and b). Arundic acid may be useful for the treatment of other neuropsychiatric diseases, such as ataxia, ${ }^{37,38}$ migraine, ${ }^{39}$ schizophrenia ${ }^{40-42}$ and depression ${ }^{43}$ as glial glutamate transporter dysfunctions exist in these neuropsychiatric diseases. Arundic acid passed a phase 1 clinical trial, ${ }^{27,44}$ so it does not cause toxicity in the central nervous system.

In addition, we demonstrated that arundic acid can enhance the EAAT1 expression in human neuroglioblastoma cells. The molecular mechanism of this enhancement appears to be activation of the genetic promoter for EAAT1, although the 
pathway for promoter activation is not known. Our studies provide potential novel neurotherapeutics for the management of glaucoma by modulating the EAAT1 activity via gene activation.

\begin{abstract}
Materials and Methods
Mice and arundic acid administration. All experiments were performed in accordance with the ethical guidelines of the Institutional Animal Care and Use Committee of Tokyo Medical and Dental University. C57BL/6 J mice were purchased from CLEA Japan (Tokyo, Japan). GLAST ${ }^{+/}$and $\mathrm{GLAST}^{-/}$mice were previously described. ${ }^{45}$ All mice used in this study were backcrossed with C57BL/6 J mice for at least 10 generations. The daily oral administrations of arundic acid $(10 \mathrm{mg} / \mathrm{kg} / \mathrm{day}$, Ono Pharmaceutical, Osaka, Japan) ${ }^{30}$ or corn oil (Sigma-Aldrich, St. Louis, MO, USA) to C57BL/6 J, GLAST $T^{+/}$and GLAST ${ }^{-1}$ mice were performed from ages P22 to $P 35$. At a dose of $10 \mathrm{mg} / \mathrm{kg}$, orally administered arundic acid was shown to exhibit inhibitory actions on cerebral amyloidosis and gliosis in Altzheimer transgenic mice. $^{30}$ The mice were killed immediately after the final administration and then their retinas were either processed for RGC counts, prepared for retinal RNA and protein extractions, or used for glutamate uptake assays.
\end{abstract}

Cell culture, transfection and luciferase assays. The primary Müller cell cultures were prepared as previously described. ${ }^{6,46,47}$ The human neuroglioblastoma $\mathrm{H} 4$ cell line was purchased from American Type Tissue Collection (Manassas, VA, USA). Müller cells, H4 cells and HEK293T cells were grown in Dulbecco's modified Eagle's medium (Sigma-Aldrich) that contained 10\% fetal bovine serum, $4.5 \mathrm{mg} / \mathrm{ml}$ D-glucose, $4 \mathrm{mM} \mathrm{L-glutamine} \mathrm{and} 1 \mathrm{mM}$ pyruvate at $37^{\circ} \mathrm{C}$ in $10 \% \mathrm{CO}_{2} / 90 \% \mathrm{O}_{2}$. HEK293T cells were transfected with EAAT1 plasmid using GeneJuice Transfection Reagent (Merck Millipore, Billerica, MA, USA). One day after transfection, cells were plated onto 12-well plates at a density of $2.0 \times 10^{5}$ cells per well and incubated for 1 day. Two days after transfection, the cells were subjected to a glutamate uptake assay. To study the effects of arundic acid on EAAT1 expression in $\mathrm{H} 4$ cells, the cells were incubated for 9 days in culture media that contained arundic acid $(0,12.5,25,50$ or $100 \mu \mathrm{M})$, and during which the media were changed every 2 days. To perform the luciferase promoter assay, after 6 days of $50 \mu \mathrm{M}$ arundic acid or DMSO treatment, $\mathrm{H} 4$ cells were transiently transfected with the pGL4.11[luc2P] (Promega, Madison, WI, USA), containing the full-length promoter region and $3^{\prime}$-UTR of EAAT1, and pGL4.73[hR/uc/SV40] (Promega), using Lipofectamine3000 (Invitrogen, Carlsbad, CA, USA). After transfection, the cells were incubated with $50 \mu \mathrm{M}$ arundic acid or DMSO for three additional days. After 9 days of treatment, the cells were harvested with $1 \times$ Passive Lysis Buffer (Promega). The luminescent signal from firefly luciferase and renilla luciferase was measured sequentially with a Lumat LB 9507 luminometer (Berthold Technologies, Bad Wildbad, Germany) using the Dual-Luciferase Reporter Assay System (Promega) according to the manufacturers' instructions. Firefly luciferase activity was normalized to renilla luciferase activity.

DNA constructs. Full-length EAAT1 cDNA (OriGene, Rockville, MD, USA) was cloned in the mammalian expression vector pcDNA3.1 (Invitrogen). Genomic DNA was extracted from $\mathrm{H} 4$ cells using a DNeasy Blood \& Tissue Kit (Qiagen, Valencia, CA, USA), and the 2.7 kilobase (kb) fragment of the EAAT1 promoter and $2.1 \mathrm{~kb}$ fragment of EAAT1 3'UTR were amplified by PCR. Primer sets were designed as follows: EAAT1 promoter forward 5'-GCTCGCTAGCCTCGAGGTAATCTCGAGTT CTTCAAACCAAT- 3 ' and reverse 5'-CCGGATTGCCAAGCTTGGTGGAAGATAT CAAGCAGTAACG-3'; and EAAT1 3 '-UTR forward 5'-AAATCGATAAGGATCCC GACAGTGAAACCAAGATGTAGAC- $3^{\prime}$ and reverse 5'-AAGGGCATCGGTCTAC AAGAATAACAACAACGTGCAAAGA-3'. The PCR product of the EAAT1 promoter was inserted between the Xhol and Hindlll sites of pGL4.11[luc2P] and cloned using an In-Fusion HD Cloning Kit (Clontech, Mountain View, CA, USA), and then the PCR product of EAAT1 $3^{\prime} U T R$ was similarly cloned following insertion between the BamHI and Sall sites of pGL4.11[luc2P].

Glutamate uptake assays. Two days after EAAT1 cDNA transfection, HEK293T cells were incubated at $37^{\circ} \mathrm{C}$ for $12 \mathrm{~min}$ in assay buffer $(137 \mathrm{mM} \mathrm{NaCl}$, $5.4 \mathrm{mM} \mathrm{KCl}, 0.4 \mathrm{mM} \mathrm{MgSO}_{4}, 0.5 \mathrm{mM} \mathrm{MgCl}, 0.64 \mathrm{mM} \mathrm{KH}_{2} \mathrm{PO}_{4}, 1.26 \mathrm{mM} \mathrm{CaCl}_{2}$, $5 \mathrm{mM}$ HEPES (pH 7.5) and $5.5 \mathrm{mM}$ D(+)-glucose) containing 1.0, 3.9, 15.6, 62.5, 250.0 or $1000.0 \mu \mathrm{M}$ of unlabeled L-glutamate. L-[3,4- $\left.{ }^{3} \mathrm{H}\right]$ glutamate $(50.6 \mathrm{Ci} / \mathrm{mmol}$, PerkinEImer Life Science, Boston, MA, USA) was added to a final concentration of $0.05 \mu \mathrm{M}$ for an additional $20 \mathrm{~min}$, following which the assay was terminated with two washes in ice-cold $\mathrm{Na}^{+}$-free assay buffer ( $\mathrm{NaCl}$ was replaced by equimolar $\left.\mathrm{LiCl}\right)$. Then the cells were immediately lysed with $0.1 \mathrm{~N} \mathrm{NaOH}$. Aliquots of the cell lysates were prepared for scintillation counting, whereas aliquots were used for the measurement of protein concentrations by a BCA kit (Sigma-Aldrich). The kinetic parameters, the Michaelis constant $\left(K_{m}\right)$ and the maximum uptake velocity $\left(V_{\max }\right)$ were determined using Hanes-Woolf plot transformations. The effects of arundic acid on the kinetics of EAAT1 glutamate uptake activity were evaluated in cells following preincubation with arundic acid $(100 \mu \mathrm{M})$ and subsequent addition of L- $\left[3,4-{ }^{3} \mathrm{H}\right]$ glutamate. In primary cultured Müller cells, the glutamate uptake assay was performed after 14 days of arundic acid treatment. Following $20 \mathrm{~min}$ of preincubation with assay buffer, glutamate uptake was terminated at $7 \mathrm{~min}$ by three washes in ice-cold $\mathrm{Na}^{+}$-free assay buffer. All results were from triplicate samples and were repeated in three separate experiments. To determine the glutamate uptake velocity of retinas from C57BL/6 J- and GLAST-deficient mice, both retinas were removed from one mouse and cut into eight pieces. Each set of four pieces was preincubated with either $\mathrm{Na}^{+}$-containing or $\mathrm{Na}^{+}$-free assay buffer and $100 \mu \mathrm{M}$ unlabeled glutamate for $20 \mathrm{~min}$. L-[3,4- $\left.{ }^{3} \mathrm{H}\right]$ glutamate was added to a final concentration of $0.05 \mu \mathrm{M}$. After 7 min of incubation, the assay was terminated by washing three times with ice-cold $\mathrm{Na}^{+}$-free assay buffer. The glutamate transport velocity was calculated by subtracting the velocity in $\mathrm{Na}^{+}$-free assay buffer from that in $\mathrm{Na}^{+}$-containing assay buffer. All results were performed in duplicate samples and were repeated in six individual mice.

Immunoblot analysis. Retinas and cultured Müller cells were homogenized in ice-cold $50 \mathrm{mM}$ Tris- $\mathrm{HCl}(\mathrm{pH} 7.5)$ containing $150 \mathrm{mM} \mathrm{NaCl}, 1 \%(\mathrm{v} / \mathrm{v})$ Nonidet P-40, $0.25 \%$ (w/v) sodium deoxycholate, $1 \mathrm{mM}$ EDTA, $1 \mathrm{mM}$ phenylmethylsulfonyl fluoride, $1 \mathrm{mM} \mathrm{NaVO}, 1 \mathrm{mM} \mathrm{NaF}$ and a proteinase inhibitor cocktail (Roche, Manheim, Germany). Samples were separated by sodium dodecyl sulfate polyacrylamide gel electrophoresis and then transferred onto polyvinylidene difluoride membranes (Merck Millipore). The following antibodies were used for immunoblotting: $1 \mu \mathrm{g} / \mathrm{ml}$ of affinity purified anti-GLAST rabbit polyclonal ${ }^{48}$ and $10 \mathrm{ng} / \mathrm{mL}$ of anti- $\beta$-actin mouse monoclonal (C4; Santa Cruz Biotechnology, Santa Cruz, CA, USA) antibodies. After incubation with primary antibodies, the membrane was incubated with horseradish peroxidase-conjugated mouse or rabbit immunoglobulin G antibodies (diluted 1:10000; Jackson ImmunoResearch Laboratories, Bar Harbor, ME, USA). Data were visualized using Luminata Forte Western HRP Substrate (Merck Millipore) and quantified by measuring the ratio of band intensities for GLAST relative to $\beta$-actin using Image Lab software (Bio-Rad Laboratories, Hercules, CA, USA).

Quantitative RT-PCR experiments. Total mRNA was isolated from retinas and cells using TRIzol reagent (Invitrogen) and then reverse transcribed into CDNA using PrimeScript RT with gDNA Eraser (Takara Bio Inc. Siga, Japan). q RT-PCR was performed to amplify mouse GLAST (accession number: NM_148938.3), GLT1 (accession number: NM_001077514.3), EAAC1 (accession number: NM_009199.2) and Rpp30 (the ortholog of human RNaseP, accession number: NM_019428.3). EAAT1 and RPPH1 (the H1 RNA subunit of the RNaseP enzyme complex, accession number: NR_002312.1) were amplified from human cells. The qPCR reactions were performed using a LightCycler 480 system II (Roche) with SYBR Premix ExTaq II (Takara Bio Inc.). The following primers were used: mouse GLAST forward $5^{\prime}$-GTCGCGGTGATAATGTGGTA-3' and reverse $5^{\prime}$-AATCTTCCCTGC GATCAAGA-3'; mouse GLT1 forward 5'-GGTCATCTTGGATGGAGGTC-3' and reverse $5^{\prime}$-ATACTGGCTGCACCAATGC-3'; mouse EAAC1 forward 5'-ACGT CACCCTGATCATTGCT-3' and reverse 5'-GACGTTCACCATGGTCCTG-3'; mouse Rpp30 forward 5'-TCCAGTGTGCAAGAAAGCTAAATG-3' and reverse $5^{\prime}$-GGCA GTGCGTGGAGACTCA-3'; human SLC1A3 forward 5'-TACCAAAGAGGAGGTT TGGC-3' and reverse 5'-GGAGGGTCTCTTCTTTGCAC-3'; and human RPPH1 forward $5^{\prime}$-AGCTGAGTGCGTCCTGTCACT- $3^{\prime}$ and reverse $5^{\prime}$-TCTGGCCCTA GTCTCAGACCTT-3'. The GPCR experiments were conducted either three or four times, with every sample run in duplicate. The samples were normalized to the relative amplifications of mouse $R p p 30$ and human $R P P H 1$.

Histological and morphometric analysis. Mice were killed at P35 and then their eyes were dissected and immersed in Davidson's fixative solution ${ }^{24}$ overnight at $4{ }^{\circ} \mathrm{C}$. The fixed eyes were dehydrated in $70 \%$ ethanol for 3 days at $4{ }^{\circ} \mathrm{C}$ and embedded in paraffin wax. Embedded eyes were sectioned at a thickness of $7 \mu \mathrm{m}$ and stained with hematoxylin and eosin. The number of neurons in the GCL was counted from one ora serrata through the optic nerve to the other ora serrata in a blind manner. The average numbers of neurons in the GCL/eyes were obtained 
from three sections of each retina. Microscopic images were obtained using a Leica DM RA microscope (Leica, Wetzlar, Germany) with a HCX PLAN APO $40 \times 10.75$ PH2 objective (Leica) and a DFC 300 FX camera (Leica), and a Leica Application Suite (Leica).

Statistical analyses. Values are expressed as the mean \pm S.E.M. Twotailed Student's $t$-tests were used for two-sample comparisons, and one-way ANOVA tests were used for multiple comparisons followed by Tukey-Kramer's or Dunnett's post hoc tests for significance, in which $P<0.05$ was regarded as statistically significant.

\section{Conflict of Interest}

The authors declare no conflict of interest.

Acknowledgements. This work was supported by the Strategic Research Program for Brain Sciences ('Understanding of molecular and environmental bases for brain health') from the Ministry of Education, Culture, Sports, Science and Technology of Japan (to KT), the Funding Program for Next Generation WorldLeading Researchers (NEXT Program; to TH), a grant from the Ministry of Education, Culture, Sports, Science and Technology of Japan (to KN), a grant from the Ministry of Health, Labor and Welfare of Japan (to TH and KT), the Suzuken Memorial Foundation (to TA) and the Joint Usage/Research Program of the Medical Research Institute at Tokyo Medical and Dental University (to TH, TA and KT).

\section{Author contributions}

MY, TA, TH and KT designed the study. MY and KT wrote the paper. MY, RS, KN and TT conducted experiments. All authors interpreted the data.

1. Quigley HA, Broman AT. The number of people with glaucoma worldwide in 2010 and 2020 . Br J Ophthalmol 2006; 90: 262-267.

2. Weinreb RN, Khaw PT. Primary open-angle glaucoma. Lancet 2004; 363 1711-1720.

3. Iwase $A$, Suzuki $Y$, Araie M, Yamamoto $T$, Abe $H$, Shirato $S$ et al. The prevalence of primary open-angle glaucoma in Japanese: the Tajimi Study. Ophthalmology 2004; 111 : $1641-1648$.

4. Heijl A, Leske MC, Bengtsson B, Hyman L, Hussein M. Early Manifest Glaucoma Trial Group Reduction of intraocular pressure and glaucoma progression: results from the Early Manifest Glaucoma Trial. Arch Ophthalmol 2002; 120: 1268-1279.

5. Harada T, Harada C, Nakamura K, Quah HM, Okumura A, Namekata K et al. The potential role of glutamate transporters in the pathogenesis of normal tension glaucoma. J Clin Invest 2007; 117: 1763-1770.

6. Harada C, Namekata K, Guo X, Yoshida H, Mitamura Y, Matsumoto Y et al. ASK1 deficiency attenuates neural cell death in GLAST-deficient mice, a model of normal tension glaucoma. Cell Death Differ 2010; 17: 1751-1759.

7. Izumi Y, Shimamoto K, Benz AM, Hammerman SB, Olney JW, Zorumski CF. Glutamate transporters and retinal excitotoxicity. Glia 2002; 39: 58-68.

8. Reichelt W, Stabel-Burow J, Pannicke T, Weichert H, Heinemann U. The glutathione level of retinal Müller glial cells is dependent on the high-affinity sodium-dependent uptake of glutamate. Neuroscience 1997; 77: 1213-1224.

9. Baltmr A, Duggan J, Nizari S, Salt TE, Cordeiro MF. Neuroprotection in glaucoma - is there a future role?. Exp Eye Res 2010; 91: 554-566.

10. Naskar R, Vorwerk CK, Dreyer EB. Concurrent downregulation of a glutamate transporter and receptor in glaucoma. Invest Ophthalmol Vis Sci 2000; 41: 1940-1944.

11. Namekata K, Harada C, Kohyama K, Matsumoto Y, Harada T. Interleukin-1 stimulates glutamate uptake in glial cells by accelerating membrane trafficking of $\mathrm{Na}+/ \mathrm{K}+-\mathrm{ATPase}$ via actin depolymerization. Mol Cell Biol 2008; 28: 3273-3280.

12. Koeberle PD, Bähr M. The upregulation of GLAST-1 is an indirect antiapoptotic mechanism of GDNF and neurturin in the adult CNS. Cell Death Differ 2008; 15 : 471-483.

13. Rothstein JD, Patel S, Regan MR, Haenggeli C, Huang YH, Bergles DE et al. Beta-lactam antibiotics offer neuroprotection by increasing glutamate transporter expression. Nature 2005; 433: 73-77.

14. Tanaka K. Antibiotics rescue neurons from glutamate attack. Trends Mol Med 2005; 11 259-262.

15. Kong Q, Chang LC, Takahashi K, Liu Q, Schulte DA, Lai L et al. Small-molecule activator of glutamate transporter EAAT2 translation provides neuroprotection. J Clin Invest 2014; 124 1255-1267.

16. Fumagalli $E$, Funicello $M$, Rauen $T$, Gobbi M, Mennini $T$. Riluzole enhances the activity of glutamate transporters GLAST, GLT1 and EAAC1. Eur J Pharmacol 2008; 578 171-176.
17. Asano T, Mori T, Shimoda T, Shinagawa R, Satoh S, Yada N et al. Arundic acid (ONO-2506) ameliorates delayed ischemic brain damage by preventing astrocytic overproduction of S100B. Curr Drug Targets CNS Neurol Disord 2005; 4: 127-142.

18. Tateishi N, Mori T, Kagamiishi Y, Satoh S, Katsube N, Morikawa E et al. Astrocytic activation and delayed infarct expansion after permanent focal ischemia in rats. Part II: suppression of astrocytic activation by a novel agent (R)-(-)-2-propyloctanoic acid (ONO-2506) leads to mitigation of delayed infarct expansion and early improvement of neurologic deficits. J Cereb Blood Flow Metab 2002; 22: 723-734.

19. Mori T, Tateishi N, Kagamiishi Y, Shimoda T, Satoh S, Ono S et al. Attenuation of a delayed increase in the extracellular glutamate level in the peri-infarct area following focal cerebral ischemia by a novel agent ONO-2506. Neurochem Int 2004; 45: 381-387

20. Harada T, Harada C, Watanabe M, Inoue $Y$, Sakagawa T, Nakayama N et al. Functions of the two glutamate transporters GLAST and GLT-1 in the retina. Proc Natl Acad Sci USA 1998; 95: 4663-4666

21. Rauen T. Diversity of glutamate transporter expression and function in the mammalian retina. Amino Acids 2000; 19: 53-62.

22. Kim SY, Choi SY, Chao W, Volsky DJ. Transcriptional regulation of human excitatory amino acid transporter 1 (EAAT1): cloning of the EAAT1 promoter and characterization of its basal and inducible activity in human astrocytes. J Neurochem 2003; 87: 1485-1498.

23. Unger T, Lakowa N, Bette S, Engele J. Transcriptional regulation of the GLAST/EAAT-1 gene in rat and man. Cell Mol Neurobiol 2012; 32: 539-547.

24. Bai N, Hayashi H, Aida T, Namekata K, Harada T, Mishina M et al. Dock3 interaction with a glutamate-receptor NR2D subunit protects neurons from excitotoxicity. Mol Brain 2013; 6: 22 .

25. Bai N, Aida T, Yanagisawa M, Katou S, Sakimura K, Mishina M et al. NMDA receptor subunits have different roles in NMDA-induced neurotoxicity in the retina. Mol Brain 2013; 6: 34 .

26. Namekata K, Kimura A, Kawamura K, Guo X, Harada C, Tanaka K et al. Dock3 attenuates neural cell death due to NMDA neurotoxicity and oxidative stress in a mouse model of normal tension glaucoma. Cell Death Differ 2013; 20: 1250-1256.

27. Pettigrew LC, Kasner SE, Albers GW, Gorman M, Grotta JC, Sherman DG et al. Safety and tolerability of arundic acid in acute ischemic stroke. J Neurol Sci 2006; 251: 50-56.

28. Oki C, Watanabe Y, Yokoyama H, Shimoda T, Kato H, Araki T. Delayed treatment with arundic acid reduces the MPTP-induced neurotoxicity in mice. Cell Mol Neurobiol 2008; 28: 417-430.

29. Traynor BJ, Bruijn L, Conwit R, Beal F, O'Neill G, Fagan SC et al. Neuroprotective agents for clinical trials in ALS: a systematic assessment. Neurology 2006; 67: 20-27.

30. Mori T, Town T, Tan J, Yada N, Horikoshi Y, Yamamoto J et al. Arundic Acid ameliorates cerebral amyloidosis and gliosis in Alzheimer transgenic mice. J Pharmacol Exp Ther 2006; 318: $571-578$.

31. Mehta A, Prabhakar M, Kumar P, Deshmukh R, Sharma PL. Excitotoxicity: bridge to various triggers in neurodegenerative disorders. Eur J Pharmacol 2013; 698: 6-18.

32. Takasaki C, Okada R, Mitani A, Fukaya M, Yamasaki M, Fujihara Y et al. Glutamate transporters regulate lesion-induced plasticity in the developing somatosensory cortex. J Neurosci 2008; 28: 4995-5006.

33. Martin KR, Levkovitch-Verbin H, Valenta D, Baumrind L, Pease ME, Quigley HA. Retinal glutamate transporter changes in experimental glaucoma and after optic nerve transection in the rat. Invest Ophthalmol Vis Sci 2002; 43: 2236-2243.

34. Schuettauf $F$, Thaler S, Bolz S, Fries J, Kalbacher $\mathrm{H}$, Mankowska A et al. Alterations of amino acids and glutamate transport in the DBA/2J mouse retina; possible clues to degeneration. Graefes Arch Clin Exp Ophthalmol 2007; 245: 1157-1168.

35. Li Q, Puro DG. Diabetes-induced dysfunction of the glutamate transporter in retinal Müller cells. Invest Ophthalmol Vis Sci 2002; 43: 3109-3116.

36. Kinnunen K, Petrovski G, Moe MC, Berta A, Kaarniranta K. Molecular mechanisms of retinal pigment epithelium damage and development of age-related macular degeneration. Acta Ophthalmol 2012; 90: 299-309.

37. Jen JC, Wan J, Palos TP, Howard BD, Baloh RW. Mutation in the glutamate transporter EAAT1 causes episodic ataxia, hemiplegia, and seizures. Neurology 2005; 65: 529-534.

38. de Vries B, Mamsa H, Stam AH, Wan J, Bakker SL, Vanmolkot KR et al. Episodic ataxia associated with EAAT1 mutation C186S affecting glutamate reuptake. Arch Neurol 2009; 66: 97-101.

39. Freilinger T, Koch J, Dichgans M, Mamsa H, Jen J. A novel mutations in SLC1A3 associated with pure hemiplegic migraine. J Headache Pain 2010; 11: 90.

40. Walsh T, McClellan JM, McCarthy SE, Addington AM, Pierce SB, Cooper GM et al. Rare structural variants disrupt multiple genes in neurodevelopmental pathways in schizophrenia. Science 2008; 320: 539-543.

41. Karlsson RM, Tanaka K, Heilig M, Holmes A. Loss of glial glutamate and aspartate transporter (excitatory amino acid transporter 1) causes locomotor hyperactivity and exaggerated responses to psychotomimetics: rescue by haloperidol and metabotropic glutamate 2/3 agonist. Biol Psychiatry 2008; 64: 810-814.

42. Karlsson RM, Tanaka K, Saksida LM, Bussey TJ, Heilig M, Holmes A. Assessment of glutamate transporter GLAST (EAAT1)-deficient mice for phenotypes relevant to the 
negative and executive/cognitive symptoms of schizophrenia. Neuropsychopharmacology 2009; 34: 1578-1589.

43. Cui W, Mizukami H, Yanagisawa M, Aida T, Nomura M, Isomura Y et al. Glial dysfunction in the mouse habenula causes depressive-like behaviors and sleep disturbance. $J$ Neurosci 2014; 34: 16273-16285.

44. Ishibashi H, Pettigrew LC, Funakoshi Y, Hiramatsu M. Pharmacokinetics of arundic acid, an astrocyte modulating agent, in acute ischemic stroke. J Clin Pharmacol 2007; 47: 445-452.

45. Watase K, Hashimoto K, Kano M, Yamada K, Watanabe M, Inoue $Y$ et al. Motor discoordination and increased susceptibility to cerebellar injury in GLAST mutant mice. Eur J Neurosci 1998; 10: 976-988.

46. Harada T, Harada C, Kohsaka S, Wada E, Yoshida K, Ohno S et al. Microglia-Müller glia cell interactions control neurotrophic factor production during light-induced retinal degeneration. J Neurosci 2002; 22: 9228-9236.

47. Harada C, Harada T, Quah HM, Maekawa F, Yoshida K, Ohno S et al. Potential role of glial cell line-derived neurotrophic factor receptors in Müller glial cells during light-induced retinal degeneration. Neuroscience 2003; 122: 229-235.
48. Shibata T, Yamada K, Watanabe M, Ikenaka K, Wada K, Tanaka K et al. Glutamate transporter GLAST is expressed in the radial glia-astrocyte lineage of developing mouse spinal cord. J Neurosci 1997; 17: 9212-9219.

(c)

Cell Death and Disease is an open-access journal published by Nature Publishing Group. This work is licensed under a Creative Commons Attribution 4.0 International License. The images or other third party material in this article are included in the article's Creative Commons license, unless indicated otherwise in the credit line; if the material is not included under the Creative Commons license, users will need to obtain permission from the license holder to reproduce the material. To view a copy of this license, visit http://creativecommons.org/licenses/by/4.0/

Supplementary Information accompanies this paper on Cell Death and Disease website (http://www.nature.com/cddis) 